Original Article

\title{
Treatment of Advanced Rectal Cancers: Cylindrical abdominoperineal excision of rectum
}

\author{
Nirmal Lamichhane ${ }^{1}$, Kenneth G walker², Angus G watson ${ }^{2}$, James Docherty ${ }^{2}$ \\ ${ }^{\mathbf{1}}$ Department of Surgical Oncology, BPKMCH, Bharatpur ${ }^{2}$ Department of Colorectal Surgery, Raigmore Hospital, Inverness, UK
}

\begin{abstract}
Treatment for patients with locally advanced low lying rectal cancer differs significantly from patients with rectal cancer restricted to the mesorectum. Surgical resection will be the straightforward option for the early ones but multimodality treatment, including preoperative chemo-radiation and extended surgical resection will be the options for advanced ones. Cylindrical abdominoperineal excision of rectum (C-APER) along with possible composite pelvic organ resection is a surgical method to remove an adequate circumferential margin so to reduce the local recurrence rate and improve long term survival. Adequate preoperative imaging of the pelvis is therefore important to identify these patients and effort should be made to select those patients with advanced tumours with no systemic spread. In this article, we reviewed some consecutive cases of advanced rectal cancer to their immediate surgical outcome.
\end{abstract}

Keywords: Rectal cancer, cylindrical abdominoperineal excision of rectum, composite organ resection, radiotherapy.

\section{INTRODUCTION:}

The majority of patients with primary rectal cancer present with a tumour located within the mesorectal fascia, which is generally treated with total mesorectal excision (TME). ${ }^{1}$ In $10 \%$ of all rectal cancer patients the tumour extends close to, into or beyond mesorectum and enveloping fascia propria ie $\mathrm{T} 3 / 4 .^{2}$ These numbers could be higher in Nepal. Some of these tumours invade the adjacent structures and therefore have a higher risk of developing local recurrence. ${ }^{3}$ Patients with these primary locally advanced rectal cancers are historically difficult to treat with surgery alone. Outcome has significantly improved using multimodality treatment. ${ }^{4}$

For low lying rectal lesions, the involvement of circumferential margin (CRM) is very common with conventional abdominoperineal excision (APE). ${ }^{5}$ This is mainly due to removal of inadequate tissue at the level of the tumour. Bearing in mind the tapering of the mesorectum toward the levators, it is important for surgeons to understand it is likely that there is less tissue for the carcinoma to traverse before involving the surgical plane of resection in the low mesorectum and anal canal. ${ }^{6}$ This usually gives rise to close CRM in APER specimens. We know that positive CRM is directly related to increased local recurrence and subsequent decrease in survival. ${ }^{7}$ This gives a clue that more aggressive/wider surgical resection is required for low lying rectal tumours to reduce the local recurrence.

There is evidence to suggest that the traditional APER may have changed over the last half century. The original description by Miles describes the abdominal dissection being performed down to the levator ani muscles, which were not incised at this point. The perineal dissection was then started, and he described a wide excision with removal of the coccyx and the removal of the levator ani by dividing them as far outwards as their origin from the 'white line' so as to include the lateral zone of spread. His description in 1910 confirms his perineal approach to the levators and he stated "these muscles are divided as far outwards as their origin from the pelvic wall." ${ }^{\text {The }}$ perineal approach and the wider excision of the levators are different from the current technique of following the mesorectal fascia down to the levators. With more wide spread use of TME, surgeons have tended to taper the specimen even for APER. The original approach of Miles would result in more tissue being excised in the low rectum and might lead to a lower rate of CRM involvement.

Recently, Dr. T. Holm of the Karolinska Institute in Stockholm has been promoting the excision of the anus and levator muscles from below with the patient lying prone. This mainly perineal approach results in a completely different resection specimen with more tissue

Correspondence

Nirmal Lamichhane, Dept of Surgical Oncology, BP Koirala Memorial Cancer Hospital, Bharatpur, Nepal. 
removed and a surgical resection margin much farther away from the muscularis propria and the sphincters. The levator muscles are included in the specimen with their natural relationships intact. Removal of the coccyx improves the access to the levator plane and facilitates the wider operation and is routinely performed by Dr. Holm in Stockholm (fig 1 and 2). ${ }^{9}$

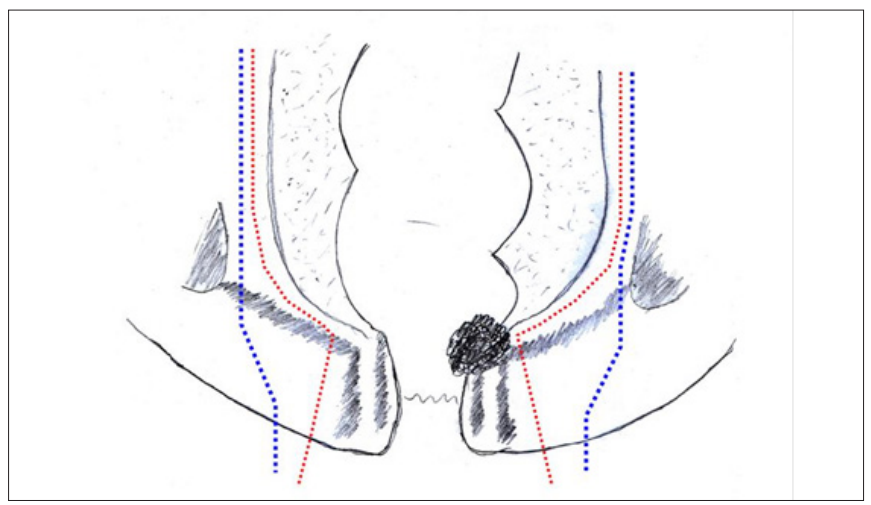

Figure 1 Diagram representation of "standard" (red lines) and cylindrical APER (blue lines), coronal plane.

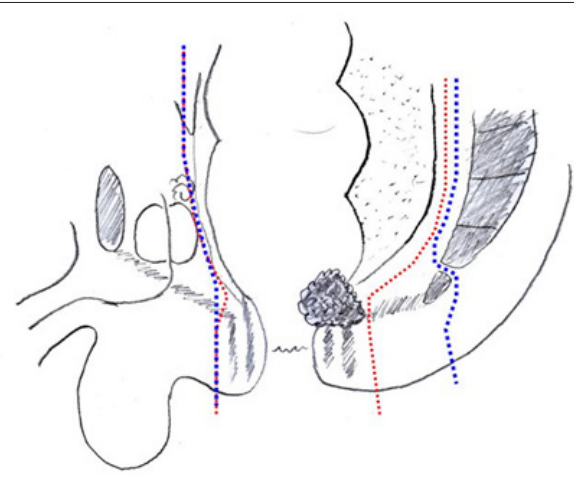

Figure 2. Diagram of "standard" (red lines) and cylindrical APER (blue lines), sagittal plane.

It is not an absolute prerequisite to remove the coccyx in this type of operation and can be omitted, but the surgical difficulty may be increased. A randomized trial of removal versus retention has not been performed. The resulting pelvic floor deficit is covered by surgical flaps or artificial mesh repair. This operation should be considered in all low rectal pT3 tumours. The greater access of the perineal approach should reduce the frequency of perforation of the specimen and, in our experience, the common problem of the surgical margin entering the muscle wall low in the rectum.

This wider surgical resection sometimes involves not only the removal of the total mesorectum, but en bloc resection of involved structures around it. This exenterative operation sometimes needs the removal of urinary bladder, prostate, vagina, uterus and adenexa.

In this report, the therapeutic approach of C-APER is taken for 5 advanced rectal cancers in 9 months period. This is discussed with a focus on multimodality treatment protocols to downstage the tumours and extended resections to enable complete removal of all tumour tissue with clear surgical margins.

\section{SURGICAL TECHNIQUE:}

The patient under general anesthetic is put in LloydDavies position with routine preparation of the abdominal part. Standard mobilization of left colon, sigmoid colon and rectum is done up to the level of about S4/5 of the vertebrae before the specimen starts to taper down. This part can be performed laparoscopically or in an open fashion. The sigmoid end stoma is matured at the left side of the abdomen at a previously marked area. The abdomen is closed and dressed. The patient is then changed to prone and jack knife position, legs slightly spread apart. A keyhole like incision is made extending form coccyx to around the anus (Figure 3 ).

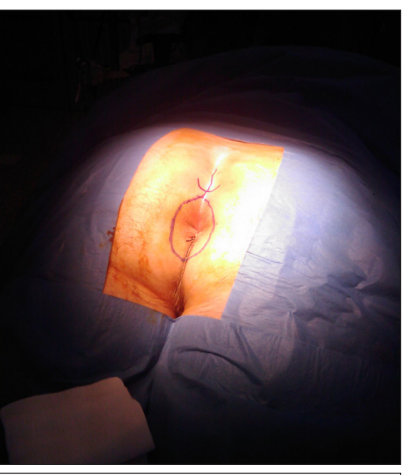

Figure 3. Pre-surgical marking at perineum

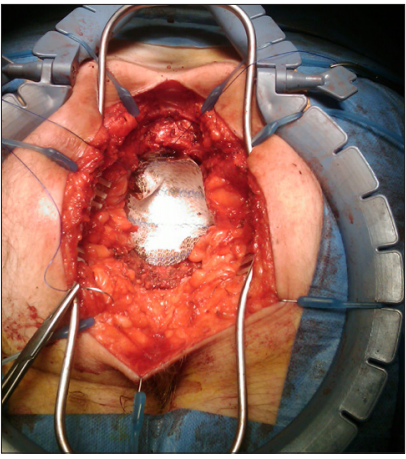

Figure 5. Perineal defect being closed with a mesh

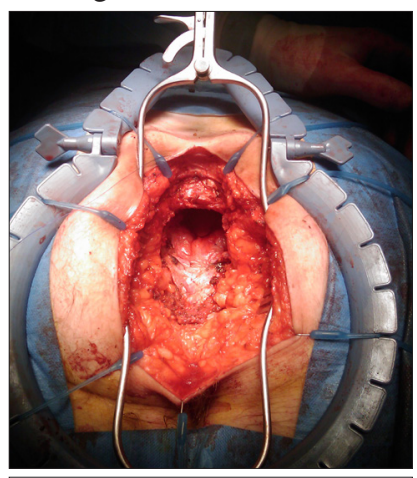

Figure 4. Perineal surgery in progress, loan star retractor in situ.

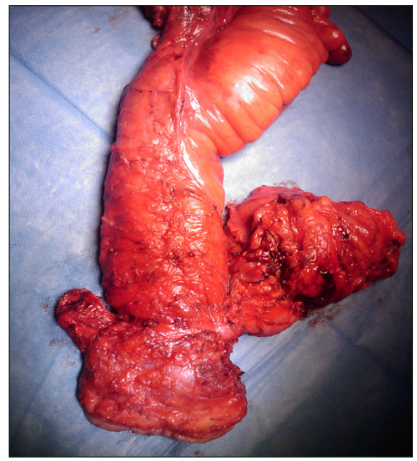

Figure 6. Specimen in situ contains coccyx posteriorly, urinary bladder and prostate in front. Levator muscles covering the specimen. 
The incision is deepened around the anus in the extrasphincteric fat plane to reach levator muscles (Figure 4). The muscles are divided wide laterally under vision and will remain attached to the rectum leaving a large pelvic floor defect. In the same plane, the coccyx is divided and kept with the specimen. The perineal plane is continued upwards to meet with the pelvic plane and the specimen is dissected out from the prostatic capsule or vaginal wall. Sometimes this anterior dissection is made easy by partly delivering the specimen. Then the specimen is delivered from the perineum. The wound lavage performed and haemostasis secured. The defect of levator muscle is closed with a biological or synthetic mesh (Figure 5). The representative delivered specimen is shown in Figure 6. Suction drains are placed above and below the mesh. The fat layer and skin are closed in layers.

The author was involved in 5 patients who were treated with this new type of surgery in a one year fellowship post. The characteristics of patients are listed in table 1 and table 2. Four patients had long course chemo and radiotherapy before surgery and had rest for 6-8 weeks before surgery. C-APER as described above was performed. One patient among these underwent pelvic exenteration for gross prostatic involvement. The pelvic floor was repaired with biological mesh in 2 and synthetic mesh in 3 . The wound complication rates were high in the perineum with serous discharge in almost every patient and one patient needing long term vacuum assisted dressing in the community.

Table 1: Pre-treatment data of the patients of APER.

\begin{tabular}{|c|c|c|c|c|c|}
\hline Case & 1 & 2 & 3 & 4 & 5 \\
\hline Age (Yr) & 75 & 64 & 72 & 69 & 66 \\
\hline Sex & Female & Male & Female & Male & Male \\
\hline Duration & $2 / 12$ & $1.5 / 12$ & $3 / 12$ & $4 / 12$ & $6 / 12$ \\
\hline Presentation & Change in bowel habit & $\mathrm{p} / \mathrm{r}$ bleed & $\mathrm{p} / \mathrm{r}$ bleed & Mucoid stool & $\mathrm{p} / \mathrm{r}$ bleed \\
\hline $\mathrm{P} / \mathrm{R}$ exam & $\begin{array}{l}\text { Tethered lesion at } 6 \mathrm{~cm} \\
\text { from the anal verge. }\end{array}$ & $\begin{array}{l}\text { Ulcerative lesions } \\
\text { at } 4.5 \mathrm{~cm} \text { form the } \\
\text { anal verge. }\end{array}$ & $\begin{array}{l}\text { Bulky lesion at } \\
\text { lower rectum }\end{array}$ & $\begin{array}{l}\text { Fixed tumor at } \\
\text { anterior wall } \\
\text { of rectum }\end{array}$ & $\begin{array}{l}\text { Tethering tumor } \\
\text { at lower rectum }\end{array}$ \\
\hline Pre op Biopsy & $\begin{array}{l}\text { Adenoca in villous } \\
\text { adenoma }\end{array}$ & Adenoca & $\begin{array}{l}\text { Poorly diff } \\
\text { mucinous } \\
\text { adenoca }\end{array}$ & Adenoca & Adenoca \\
\hline MRI & CRM compromised & $\begin{array}{l}\text { Pelvic nodes } \\
\text { present near the } \\
\text { levator muscles }\end{array}$ & $\begin{array}{l}\text { Levator Muscle } \\
\text { invasion }\end{array}$ & $\begin{array}{l}\text { Prostatic } \\
\text { capsule } \\
\text { invasion }\end{array}$ & $\begin{array}{l}\text { Mesorectal } \\
\text { nodes } \\
\text { compromizing } \\
\text { the CRM. }\end{array}$ \\
\hline CT & $\begin{array}{l}\text { Solitary Liver } \\
\text { metastasis }\end{array}$ & No distant mets & $\begin{array}{l}\text { No distant } \\
\text { mets }\end{array}$ & $\begin{array}{l}\text { No distant } \\
\text { mets }\end{array}$ & No distant mets \\
\hline $\mathrm{Hb} \%$ & 120 & 130 & 91 & 140 & 136 \\
\hline Albumin & 30 & 36 & 40 & 36 & 40 \\
\hline Colonoscopy & Full & Full & Full & Full & Full \\
\hline
\end{tabular}

Abbreviations: P/R: per rectal, MRI: magnetic resonance imaging, CT: computed tomography, CRM: circumferential margin, $\mathrm{Hb}$ : hemoglobin. 
Table 2: Treatment received

\begin{tabular}{|l|l|l|l|l|l|}
\hline \multicolumn{1}{|c|}{ Case } & \multicolumn{1}{|c|}{1} & \multicolumn{1}{c|}{2} & \multicolumn{1}{c|}{4} & \multicolumn{1}{c|}{5} \\
\hline Neoadjuvant chemo+RT & $5 / 52$ & $5 / 52$ & non & $5 / 52$ & $5 / 52$ \\
\hline Surgery & $\begin{array}{l}\text { Lap abdominal } \\
\text { and Open perineal } \\
\text { surgery. }\end{array}$ & $\begin{array}{l}\text { Open abdominal } \\
\text { and perineal } \\
\text { surgery }\end{array}$ & $\begin{array}{l}\text { Open abdominal } \\
\text { Open abdominal } \\
\text { and perineal } \\
\text { surgery } \\
\text { colon and bladder } \\
\text { and prostate. } \\
\text { Prone perineal } \\
\text { surgery }\end{array}$ & $\begin{array}{l}\text { Lap abdominal } \\
\text { surgery and open } \\
\text { perineal surgery }\end{array}$ \\
\hline $\begin{array}{l}\text { Mesh used in pelvic } \\
\text { repair }\end{array}$ & Permacol & Proceed & Permacol & Proceed & Proceed \\
\hline
\end{tabular}

Permacol: Biological Bovine collagen Mesh, Proceed: Polypropylene synthetic mesh

Table 3: Pathology

\begin{tabular}{|l|l|l|l|l|l|}
\hline \multicolumn{1}{|c|}{ Case } & \multicolumn{1}{c|}{1} & \multicolumn{1}{c|}{ 2 } & \multicolumn{1}{c|}{ - } & \multicolumn{1}{c|}{5} \\
\hline Histology & $\begin{array}{l}\text { Adenocarcinoma in } \\
\text { villous adenoma. }\end{array}$ & Adeno ca & $\begin{array}{l}\text { Poorly diff mu- } \\
\text { cinous adenoca }\end{array}$ & $\begin{array}{l}\text { Poorly diff } \\
\text { adenoca }\end{array}$ & Adeno ca \\
\hline Grade & G2 & G2 & G3 & G3 & G2 \\
\hline Lymphovascular invasion & - & - & + & + & - \\
\hline Nodal involvement & $3 / 14$ & $0 / 8$ & $0 / 13$ & $0 / 11$ & $0 / 9$ \\
\hline TNM & yPT3,yPN2, yM1 & yPT3,yPN0, M0 & T1,N0, M0 & yPT4,yPN0, M0 & yPT3, yPN0, M0 \\
\hline CRM from the disease & Not involved & $11 \mathrm{~mm}$ & Not involved & Not involved & $4.5 \mathrm{~mm}$ \\
\hline
\end{tabular}

Abbreviations: TNM: tumor, nodes, metastasis;

\section{DISCUSSION:}

For low lying advanced rectal tumours, the main strategy to attain local control and prolong survival is by multimodality treatment. Before commencing treatment, accurate imaging of the disease for staging is very important. MRI (CT scans) is the method of choice for the local staging of T3/4 tumours. 10 Endorectal ultrasound is good for T1/2 tumours. CT scan of chest and abdomen will assess for distant metastasis.

Long course chemoradiotherapy of 5 weeks and waiting time of 6-8 weeks is optimal for ideal tumour shrinkage. 11 In our series, cylindrical abdomino-perineal resection in prone position (C-APER) is chosen as the main surgical technique as described by Dr Holm in Sweden. The main difference from the conventional surgery is the anus and levator muscles are excised from below with the patient lying in prone position. This mainly perineal approach results in a completely different resection specimen with more tissue removed and a surgical resection margin much farther away from the muscularis propria and the sphincters (Figure 1 and 2). The levator muscles are included in the specimen with their natural relationships intact. Removal of coccyx improves the access to the levator plane and facilitates the wider operation. 12 The perineal defect was closed with a mesh (biological or synthetic) and closed over a drain. Other theoretical benefits are low rate of positive CRM, less intraoperative bowel perforations which translates into low local recurrence rate. Obviously the length operative time and of hospital stay and perineal wound-related complications are high. 18

West NP et al form European Extralevator Abdominoperineal Excision Study group described the wider extra levator resection of the rectal stump and showed the CRM is less involved but the perineal wound complication rate is high. 13 The same group in Journal of Clinical Oncology reported the cylindrical technique removed more tissue in the distal rectum and in all slices that contained tumour compared with the 
standard operation (both $\mathrm{p}<0.0001$ ). Greater distance was observed from the muscularis propria or internal sphincter to the anterior, posterior, and lateral resection margins (all $\mathrm{p}<0.0001)$. This was associated with lower circumferential resection margin (CRM) involvement $(14.8 \% \quad \mathrm{v}$ 40.6\%; $\mathrm{p}=0.013)$ and intra-operative perforations $(3.7 \%$ v $22.8 \% ; \mathrm{p}=0.0255)$. An increase in the amount of tissue removed in the distal rectum $(\mathrm{p}<0.0001)$ was demonstrated by a single surgeon who changed from the standard to the cylindrical technique during the study period; the change was associated with a reduction in CRM positivity (from $36.2 \%$ to $12.5 \%$ ) and in perforations (from $12.8 \%$ to $0.0 \%$ ). They concluded this technique has the potential to improve patient outcomes substantially if appropriate surgical education programs are developed. 14 Dalton et al., also concluded the prone position elAPE has a low circumferential resection margin involved rate and, through improved vision, reduces the risk of inadvertent tumour or specimen perforation. ${ }^{17}$

Youssef $\mathrm{H}$ et al form Birmingham tried to analyze the root cause of the positive CRM in APR which was 26\% in their study of 156 patients. Though there was obvious underestimation of CRM by MRI in 4 patients, the rest of the patient have no obvious cause for the involvement of CRM. 15

In the cases where we did C-APER, none of the CRM was involved. This may be the contribution of pre-operative $\mathrm{RT}$ as well as the surgical method chosen in which more tissue is excised in prone position. C-APER would be the optimal technique for local disease clearance. Long term follow up studies will be necessary to show the local control rate and overall survival for this method.

Traditionally we have had a lower threshold for giving neo-adjuvant long-course chemoradiotherapy to low rectal cancers, than to mid or upper rectal cancers. T2, 3 or 4 cancers in the low rectum may be given such multimodality treatment, whereas in the mid rectum it is currently reserved for advanced T3 or T4 tumours (ie "margin-threatening"). The reason for this was the higher incidence of positive CRM and local recurrence after APER than after TME. However we may now reconsider this policy since adopting Cylindrical APER, if on longer follow-up it appears to abolish this difference.
Regarding complications, there are increased perineal wound complications in this group of patients which will be a trade off for the better local control and possible increased survival. Other authors used gluteal flap rotation and some other techniques of plastic surgical procedures to reduce the perineal wound complications. ${ }^{16}$

So we conclude, C-APER is promising in terms of getting clear CRM, which we predict will reduce local recurrence and in the long term will translate into improved survival. The operation is technically feasible with some modifications in centers which are performing APER operations already.

\section{REFERENCES:}

1. Beart R W. Multidisciplinary Management of Patients with Advanced Rectal Cancer. Clin CancerRes. 2007; 13(22): 6890-93.

2. de Wilt JHW, Vermaas M, Ferenschild FTJ, Verhoef C. Management of Locally Advanced Primary and Recurrent Rectal Cancer. Clinics in colon and rectal surgery. 2007; 20(3): 255-263.

3. Holm T,CedermarkB, Rutqvist LE. Local recurrence of rectal adenocarcinoma after 'curative' surgery with and without preoperative radiotherapy. $\mathrm{Br} \mathrm{J}$ Surg. 1994; 81:452- 455.

4. Balch GC, DeMeo A, Guillem JG. Modern management of rectal cancer: A 2006 update. World J Gastroenterol. 2006; 12(20): 3186-3195.

5. Dulk M D, Marijnen CAM, Putter H, et al. Risk Factors for Adverse outcome in patients with rectal cancer treated with an abdominoperineal resection in the total mesorectal excision trial. Ann Surg. 2007; 246: 83-90.

6. Birbeck KF, Macklin CP, Tiffin NJ, et al. Rates of circumferential resection margin involvement vary between surgeons and predict outcomes in rectal cancer surgery. Annals of surgery. 2008; 235(4): 449-457.

7. Quirkea P, Steelec R, Monson J. Effect of the plane of surgery achieved on local recurrence in patients with operable rectal cancer: a prospective study using data from the MRC CR07 and NCIC-CTG CO16 randomized clinical trial. Lancet. 2009; 373(9666): 821-828.

8. Keighley R B M, Williams NS ed. Surgery of anus 
rectum and colon. 2nd edition. London. WB sounders. 1997. page 1119.

9. Sjövall A, Granath F, Cedermark B, Glimelius B, Holm T. Loco-regional Recurrence from Colon Cancer: A Population-based Study. Annals of Surgical Oncology 2009; 14(2): 432-440.

10. Brown B G, Daniels IR, Norman AR, Mason B, Cunningham D. MRI directed multidisciplinary team preoperative treatment strategy: the way to eliminate positive circumferential margins? British Journal of Cancer. 2006; 94: 351 - 357.

11. Guillem J G, Chessin D B, Cohen A M, et al. Longterm Oncologic Outcome Following Preoperative Combined Modality Therapy and Total Mesorectal Excision of Locally Advanced Rectal Cancer. Ann Surg. 2005; 241: 0829-838.

12. Marr R, Birbeck K, Garvican J, et al. The Modern Abdominoperineal Excision: The Next Challenge After Total Mesorectal Excision. Ann Surg. 2005; 242: 74-82.

13. West NP, Anderin C, Smith KJ, Holm T, Quirke P. Multicentre experience with extralevator abdominoperineal excision for low rectal cancer.
Br J Surg. 2010; 97(4): 588-99.

14. West NP, Finan PJ, Anderin C, Lindholm J, Holm T, Quirke P. Evidence of the oncologic superiority of cylindrical abdominoperineal excision for low rectal cancer. J Clin Oncol. 2008; 26(21):3517-22.

15. Youssef H, Collantes EC, Rashid SH, Wong LS, Baragwanath P. Rectal cancer: involved circumferential resection margin - a root cause analysis. Colorectal Dis. 2009; 11(5): 470-4.

16. Holms T, Ljung A, Haggmark T, et al. Extended abdominoperineal resection with gluteus maximus flap reconstruction of the pelvic floor for rectal cancer. Br J Surg 2007; 94: 232-238.

17. Dalton RS, Smart NJ, Edwards TJ, Chandler I, Daniels IR. Short-term outcomes of the prone perineal approach for extra-levator abdominoperineal excision (elAPE). Surgeon. 2012; 10(6): 342-6.

18. Perdawood SK, Lund T. Extralevator versus standard abdominoperineal excision for rectal cancer. Tech Coloproctol. 2015; 19(3): 145-52. 